\title{
Compositional and functional consequences of environmental change in Belgian farmland ponds
}

\author{
Laura Verbeek $^{1, *}$ (D) | Matthias Vanhamel ${ }^{2, *}$ | Edwin van den Berg ${ }^{2}$ | \\ Fabio T. T. Hanashiro ${ }^{2}$ | Andros T. Gianuca ${ }^{2,5,6}$ | Maren Striebel $^{1}$ | Pieter Lemmens ${ }^{2}$ | \\ Steven A. J. Declerck ${ }^{3}$ | Helmut Hillebrand ${ }^{1,4}$ | Luc De Meester ${ }^{2}$
}

${ }^{1}$ Institute for Chemistry and Biology of the Marine Environment, University of Oldenburg, Wilhelmshaven, Germany

${ }^{2}$ Laboratory of Aquatic Ecology, Evolution and Conservation, KU Leuven, Leuven, Belgium

${ }^{3}$ Netherlands Institute of Ecology (NIOOKNAW), Wageningen, The Netherlands

${ }^{4}$ Helmholtz Institute for Functional Marine Biodiversity (HIFMB), Oldenburg, Germany

${ }^{5}$ German Centre for Integrative Biodiversity Research (iDiv), Halle-Jena-Leipzig,

Deutscher Platz 5e, 04103 Leipzig,

Germany

${ }^{6}$ Department of Community Ecology, Helmholtz Centre for Environmental Research - UFZ, Theodor-Lieser-Str. 4, D-06120 Halle, Germany

\section{Correspondence}

Laura Verbeek, Institute for Chemistry and Biology of the Marine Environment,

University of Oldenburg, Wilhelmshaven,

Germany.

Email: laura.verbeek@uni-oldenburg.de

Funding information

Federaal Wetenschapsbeleid;

Bundesministerium für Bildung und

Forschung; Conselho Nacional de

Desenvolvimento Científico e Tecnológico,

Grant/Award Number: 245629/2012-2,

245968/2012-1

\begin{abstract}
1. A resampling of 38 small farmland ponds in Belgium after 10 years revealed a high temporal species turnover for both phytoplankton and zooplankton communities, associated with substantial changes in abiotic factors, especially a reduction in total phosphorus concentration.

2. Across ponds, phytoplankton biomass decreased while evenness and richness increased between the samplings in 2003 and 2013. By contrast, the zooplankton assemblage was characterised by lower biomass, richness and evenness in 2013. Ponds experiencing larger environmental change showed stronger changes in phytoplankton richness and evenness.

3. Resource use efficiency (RUE) of zooplankton increased with greater environmental change and zooplankton evenness, which points to a switch towards species with higher RUE or greater variety in food sources in higher trophic levels.

4. As ponds are important habitats for freshwater biodiversity and ecosystems services, the strong but predictable species turnover and the opposing effects of environmental change on different trophic levels need to be embedded in conservation and management plans.
\end{abstract}

\section{KEYWORDS}

biodiversity, community dynamics, eutrophication, species turnover, trophic levels

\section{1 | INTRODUCTION}

Among freshwater systems, small lakes and ponds ( $<1$ hectare) provide important ecosystem services such as fish production, water regulation, recreational use and intrinsic aesthetical value (Millenium Ecosystem Assessment, 2010). From a conservation perspective, these small waterbodies function as hotspots of biodiversity, with a high diversity of phyto- and zooplankton, invertebrate and plant

*Laura Verbeek and Matthias Vanhamel should be considered joint first author. species (Céréghino, Boix, Cauchie, Martens, \& Oertli, 2014; Declerck et al., 2005; Scheffer et al., 2006; Williams et al., 2004). At the landscape scale, sufficiently large ponds or clusters of ponds are also important habitats for larger organisms, for example birds, amphibians and mammals (Redfern, Grant, Gaylard, \& Getz, 2005). Thereby, small ponds contribute strongly to regional (gamma) diversity (Williams et al., 2004).

At the same time, small freshwater habitats are prone to environmental change as they are influenced by both local and regional changes in environmental conditions, including human impact, such 
as eutrophication or pollution. They are highly susceptible to changes of the surrounding land use, changes in regional climate (temperature, rainfall) or other, more localised changes (Céréghino, Biggs, Oertli, \& Declerck, 2008; Declerck et al., 2006). Therefore, ponds are ideal natural systems to study biodiversity and ecosystem processes in a global change context, because their small size, relative simplicity and often isolated nature in a terrestrial matrix makes observational studies feasible (De Meester et al., 2005). Ponds have been used as empirical examples for nonlinear compositional and functional responses to environmental change, where a small change in an abiotic driver may cause a cascade of intensifying effects. This may lead to regime shifts, which are defined as the sudden shift of the whole ecosystem from one stable state (e.g. clear-water state in ponds) to a different stable state (e.g. turbid water state) (Scheffer, Hosper, Meijer, Moss, \& Jeppesen, 1993; Scheffer \& Carpenter, 2003). Ponds allow us to monitor compositional and functional changes in ecosystems in response to environmental stressors (Adrian et al., 2009; Tranvik et al., 2009) as well as the interaction between altered species composition and ecosystem structure and processes.

Whether a change in function is directly linked to a change in composition depends on the correlation between "response" and "effect" traits. A response trait (e.g. temperature tolerance) causes the change in composition with environmental change (e.g. warming), while an effect trait mediates biotic ecosystem processes (e.g. phosphorus uptake and growth rates, grazing rates) (Hillebrand \& Matthiessen, 2009; Suding et al., 2008; Violle et al., 2007). If response and effect traits are strongly correlated, the stability of functional parameters will be linked to the stability of community composition, and vice versa, if ecosystem functions feedback into coexistence. Mineralisation rates, for example, influence the resource supply, which decides how many species can locally coexist (see Cardinale, Bennett, Nelson, \& Gross, 2009). Alternatively, altered species composition can buffer against functional change, as the community composition adapts to the altered conditions while functions remain relatively constant. Species turnover between functionally redundant species can provide such a functional insurance effect (Cottingham, Brown, \& Lennon, 2001; Yachi \& Loreau, 1999).

Most studies on the response to environmental change focus on single aspects of the response or the effect framework, often relying on single trophic groups or few variables reflecting compositional or functional change. There is, however, ample evidence that responses to environmental change differ between trophic groups and results are sensitive to the different diversity metrics used. Autotrophs show positive or negative trends in richness with fertilisation, depending, for example, on ecosystem type, but higher nutrient availability almost always leads to lower evenness (higher dominance) (Hillebrand, Bennett, \& Cadotte, 2008; Hillebrand et al., 2007). By contrast, consumer diversity might not react in the same way as primary producer diversity to changes in nutrient supply (Mittelbach et al., 2001; Striebel, Singer, Stibor, \& Andersen, 2012). Recently, the use of turnover metrics in addition to simple univariate measures of diversity such as richness or evenness has been strongly encouraged, as the latter underestimate the extend of compositional change (Dornelas et al., 2014; Hillebrand et al., 2017).

Likewise, the measurement of functional changes has moved from simple measures of standing stock to the somewhat more processrelated resource use efficiency (RUE) as the ratio of biomass (or biomass production) per unit available resource (Hillebrand \& Matthiessen, 2009; Ptacnik et al., 2008; Reiss, Bridle, Montoya, \& Woodward, 2009). RUE thus reflects the availability of resources as well as the resource requirements of individual species and is a direct measure of the transfer of organic material and energy through a food web (Elser et al., 2000). For example, Filstrup, Hillebrand, Heathcote, Harpole, and Downing (2014) showed in an analysis across $>100$ lakes in lowa how phytoplankton RUE (biomass of primary producers scaled to resource availability) decreased with evenness and temporal species turnover, whereas RUE at the zooplankton level (biomass of zooplankton scaled to biomass of primary producers) was maximised at high algal evenness and temporal turnover.

Despite such examples, the simultaneous assessment of the temporal changes in environment, species composition, biodiversity and function is rare. Only a simultaneous assessment of abiotic and biotic parameters allows addressing links between environmental, compositional and functional change. In 2013, we resampled 38 Belgian ponds 10 years after a first sampling campaign in 2003. In designing the study, we did not make any assumptions on whether the ponds showed linear or nonlinear temporal trends between the two sampling years, nor did we assume that the 2 years are representative for different time periods. However, we assumed - and found - that the large number of ponds provided us with a sample covering different magnitudes in the relative change in environmental conditions.

In the 2003 campaign, ponds were selected representing different land-use intensities at the local scale (De Bie et al., 2012). This hierarchically structured sampling avoided regional bias, for example regarding the intensity of agricultural use. Comparability between sampling years was optimised by adopting the original sampling and analysis protocol from 2003 also in 2013, and by species identification and abundance assessment that avoids potential artefacts (see Methods). We used this unique data set to simultaneously quantify changes in environmental conditions (temperature, $\mathrm{pH}$, conductivity, $\mathrm{N}$ - and P-concentrations, fish presence/absence, vegetation cover and pond morphology), species composition and ecosystem function (here: RUE). As we addressed two trophic levels, phyto- and zooplankton, we were able to test the following hypotheses:

H1: The magnitude of compositional change (richness and evenness) correlates positively to the magnitude of environmental change (total change overall abiotic variables), that is with greater environmental change comes greater compositional change.

H2: The magnitude of functional change increases with larger environmental change $(\mathrm{H} 2 a)$, but correlates not or negatively (redundancy) or positively (loss of functionally important species) with compositional turnover ( $\mathrm{H} 2 b)$. 
We use RUE of both phyto- and zooplankton as our focal function, which we relate to the magnitude of change in the environment and community composition. For phytoplankton, this is the biomass per unit resource and for the zooplankton biomass per unit algae.

H3: Responses to environmental change in terms of composition and function differ across trophic levels. This difference can comprise the sign and the magnitude of the response, as well as which abiotic variable drives the response at different levels. For example, we expect that the phytoplankton communities primarily respond to changes in resource levels, whereas zooplankton communities are more indirectly affected via changes in phytoplankton.

\section{2 | MATERIAL AND METHODS}

\section{1 | Rationale}

Addressing hypotheses $\mathrm{H} 1$ to $\mathrm{H} 3$ requires a broad set of local habitats which have undergone different magnitudes of change in abiotic conditions. We took advantage from the MANSCAPE project (De Bie et al., 2012; Declerck et al., 2006), which sampled ponds throughout Belgium once in summer 2003 (between July and September) to determine the effects of local land use (approximately within $100 \mathrm{~m}$ radius, see Declerck et al. (2006)) on the ecological state of small farmland ponds. Declerck et al. (2006) aimed at an as evenly as possible distribution of ponds throughout Belgium to cover regional variation in environmental settings. Ponds were grouped according to three levels of intensity of land agricultural use: intensive agriculture (cropland), extensive agriculture (pastures) or no agriculture (natural surroundings, e.g. in conservation areas) as assessed in the immediate surroundings of the ponds. In 2013, we resampled 38 ponds (Appendix S1) from the original selection of ponds from MANSCAPE. We have no information on how the ponds changed in between the samples, but assumed that each of the pond had changed in abiotic conditions as a consequence of temporal trends from 2003 to 2013 and unique differences between sampling years and timing. The different magnitude of environmental change across the 38 ponds was then used as driver to analyse response magnitudes in composition $(\mathrm{H} 1)$ and function $(\mathrm{H} 2)$ and the difference in response between trophic levels $(\mathrm{H} 3)$.

\section{2 | Sampling procedure 2013}

The ponds ( $n=38$ ) were resampled following the protocol of Declerck et al. (2006) for the same set of local environmental variables during summer 2013 (June-September). Pond depth was measured at the centre of each pond using a graduated stick, whereas pond surface area was assessed by measuring two perpendicular diameters and approximating pond shape. Water transparency was quantified in the field with a Snell's tube (Louette \& De Meester, 2005). Water temperature, $\mathrm{pH}$, daytime oxygen concentration and conductivity were measured in situ using a HACH HQ30D digital multimeter (Hach $\mathrm{NV}$, Mechelen, Belgium). Chl- $a$ was used as proxy for phytoplankton biomass and was measured in vivo using a TURNER handheld fluorometer (Turner Designs, U.S.A.). Chl- $a$ is the key photosynthesis pigment in phytoplankton and therefore often used as a proxy of phytoplankton biomass. To ensure that it was suitable in this case, we correlated particulate organic carbon with $\mathrm{Chl}-a$ measurements and obtained $r=.6(p<.0001)$, which is why we consider it appropriate to continue with Chl-a. The percentage of pond surface area covered with aquatic vegetation was visually estimated.

Depth-integrated water samples were collected in the open water from the middle of the largest open water patch of each pond using a tube sampler (length $1.5 \mathrm{~m}$; diameter $75 \mathrm{~mm}$ ). A beaker $(1 \mathrm{~L})$ was used instead of a tube sampler in very shallow ponds $(<20 \mathrm{~cm})$. The collected water was filtered over a $2 \mathrm{~mm}$ sieve to remove larger debris. Subsamples were subsequently taken for further analysis of nutrient concentrations $(50 \mathrm{ml})$ and suspended solids $(1 \mathrm{~L})$ in the laboratory. These samples were kept cool and in the dark until arriving at the laboratory. The amount of suspended solids was determined gravimetrically in the laboratory by filtering a known volume of pond water on preweighted GF/F filters (Whatman, GE Healthcare, U.K.). Samples for nutrient analysis were frozen at $-20^{\circ} \mathrm{C}$ until measurement of total concentrations of nitrogen and phosphorus on a Technicon Auto-Analyzer II (Technicon, Tarrytown, NY, U.S.A.) after persulphate digestion (Grasshoff, Kremling, \& Ehrhardt, 2007). An additional subsample $(250 \mathrm{ml})$ was taken and fixed with Lugol's iodine solution for later determination of phytoplankton community composition.

The zooplankton community was sampled by collecting an additional depth-integrated water sample by pooling water from four different locations in the pond using a tube sampler. This water sample was filtered over a $4 \mathrm{~mm}$ sieve to remove plant material and other larger debris, and $40 \mathrm{~L}$ was subsequently poured through a conical zooplankton net (64 $\mu \mathrm{m}$ mesh size). Zooplankton community samples were collected in $50-\mathrm{ml}$ vials and preserved with $4 \mathrm{ml}$ of $37 \%$ sugarsaturated formalin.

The presence/absence of fish was determined in each pond by point abundance sampling (see De Bie et al., 2012) with an electric fishing device suitable to also catch relative small fish (body size: 5 $12 \mathrm{~cm})$.

\subsection{Response variables}

Phytoplankton community composition was assessed as abundance data of cell counts according to the Utermöhl technique (Utermöhl, 1958) via identification to the species level, when possible. To avoid differences simply based on different people counting the samples for 2003 and 2013, respectively, we grouped all phytoplankton counts back to the genus level for data-analysis. Using genus richness has been successfully implemented as a reliable taxonomic resolution in other large-scale comparisons of biodiversity in phytoplankton (Ptacnik et al., 2008). We used genus richness as a measure of the number of taxa, and Pielou's $J$ (Pielou, 1966) as a 
measure of evenness. Additionally, we quantified genus turnover between the two sampling years with two metrics, the Jaccard index based on presence-absence data and the Bray-Curtis index that takes relative abundances into account (Bray \& Curtis, 1957; Jaccard, 1912; Oksanen et al., 2013).

Zooplankton individuals were counted using an Olympus ZSX12 stereomicroscope (Olympus Belgium SA/NV, Belgium). For each sample, 300 individuals were counted except for when a new species was found in the last 100 individuals, in which case counting was continued up to 400 individuals. Cladocerans were identified up to species level for Daphnia, Alona, Pleuroxus, Scapholeberis and Simocephalus and to genus level for Chydorus and Ceriodaphnia using (Flössner, 2000). Ostracods were counted as a group and copepods were classified into nauplius larvae, calanoids or cyclopoids. Counts were standardised to density per litre. To obtain biomass data, 15 randomly selected animals for each species in each pond were measured to determine average body size and later transformed to biomass per litre ( $\mu \mathrm{g} / \mathrm{L})$ using a conversion factor table constructed from literature (Bottrell, 1976; Dumont, Van de Velde, \& Dumont, 1975). We did not consider the very small zooplankton such as rotifers and ciliates, but instead focused on crustacean zooplankton, because biomass-wise and in terms of grazing they are dominant in these systems (at least in late spring and summer). Pielou's J (Pielou, 1966) and species richness were calculated as measures of biodiversity, Jaccard and Bray-Curtis dissimilarities as measures of species turnover.

The functional change in phytoplankton and zooplankton was calculated as the change in RUE (Filstrup et al., 2014; Ptacnik et al., 2008). For phytoplankton (RUE $E_{\mathrm{PP}}$ ), RUE was calculated as unit Chl-a $(\mu \mathrm{g} / \mathrm{L})$ per unit phosphorus $(\mu \mathrm{g} / \mathrm{L})$; for zooplankton, it was calculated as unit dry weight $(\mu \mathrm{g} / \mathrm{L})$ per unit $\mathrm{Chl}-a(\mu \mathrm{g} / \mathrm{L})$ (corresponding to a transfer efficiency, RUEZP). RUE is a dimensionless ratio indicating the transfer efficiency of mineral resources into phytoplankton biomass or of algal prey biomass into zooplankton biomass. We used total phosphorus (TP) as the basis for RUE of phosphorus limitation in most freshwater systems (Sterner, 2008). It should be noted that RUE is not equivalent to the rate of biomass production as it relies on an estimate of standing stock, but it presents a ratio between the realised (biomass) to the potential (available resource) productivity and has been proven highly successful in analyses of diversity-function relationships (Ptacnik et al., 2008).

To quantify the magnitude of change between samplings, we used log response ratios for all individual environmental variables, biodiversity measures (richness and evenness) and functions as log response ratios, $L R=\ln \left(X_{2013} / X_{2003}\right)$. Here, $X$ denotes any of the above-mentioned response variables, as measured in 2003 and 2013. A positive LR indicates an increase in the given variable, while a negative $L R$ indicates a decrease. A significant $t$ test of the LR against 0 indicates an overall negative or positive change across all ponds.

To quantify the overall abiotic change, we used nine morphometric and environmental factors (depth, surface area, temperature, $\mathrm{pH}$, conductivity, TP, total nitrogen [TN], percentage of vegetation cover, fish presence/absence, see Appendix S2) for a standardised principal component analysis (PCA). Three ponds had missing values and were excluded from the analysis, reducing $\mathrm{N}$ to 35 . We quantified the

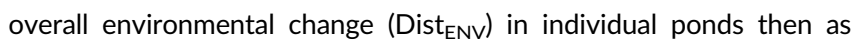
the standardised Euclidean distance between PCA positions in 2003 and 2013.

\section{4 | Statistical analysis}

With variation partitioning based on standardised redundancy analysis (RDA), we estimated the amount of variation in the abiotic environment that can be explained by differences among years (2003 versus 2013) and variation among ponds ("Pond Identity"). Variation partitioning was also applied to analyse compositional variation in phytoplankton and zooplankton communities. These analyses were based on distance-based RDA (dbRDA). For each plankton group, we performed analyses using two distance metrics, that is Bray-Curtis distance using relative abundance data and Jaccard distance using presence-absence data. Significance tests of the standardised RDA on environmental variables and dbRDAs on community data were all based on 999 random permutations following a split-plot design, with ponds being whole plots and year-specific data within ponds being split plots. Whole plots were permuted randomly. Split plots were permuted randomly but restricted to the within-pond level.

We tested our hypotheses at a general level by correlating Dis$t_{E N V}$, our measure of total environmental change (Euclidean distance), to the different measures of compositional change (BrayCurtis and Jaccard dissimilarities, LR richness, LR evenness) for both trophic levels (phytoplankton and zooplankton). A significant correlation would support hypothesis H1. Likewise, we tested for significant correlations between Dist ENV $_{\text {and }}$ measures of functional change (LR RUE $E_{P P}$ and $L R R U E_{Z P}$ ) for $\mathrm{H} 2 \mathrm{a}$, whereas the correlation between compositional and functional change tested $\mathrm{H} 2 \mathrm{~b}$. Any difference in the presence or direction of a relationship between phyto- and zooplankton would support $\mathrm{H} 3$.

At a more resolved level, we tested for the identity of the environmental variables associated with the changes in biotic composition. We used linear models with the change in abiotic environmental variables (as LR) as predictors and each of the measures of biodiversity change as response variables (LR of richness and evenness as well as both measures of species turnover). In addition to the nine variables included in the PCA, we also added the biomass change in both trophic levels as predictors. The initial full model thus comprised 11 variables (Table 1) and was then reduced using the Akaike information criterion (package MASS in R) to derive the most parsimonious model (Burnham \& Anderson, 2002). As compositional dissimilarity between years is not a directional variable, GLM (general linear models) were run with absolute log response ratios (independent of sign) as predictors of Bray-Curtis and Jaccard dissimilarities.

We added a sensitivity analysis after finding substantial environmental and compositional changes between 2003 and 2013. This poses the question whether the ponds in 2013 exhibit qualitatively different limnological patterns than in 2003, which would indicate a systematic bias in the data. Therefore, we provided Pearson 
TABLE 1 Summary of basic limnological relationships across years (2003 and 2013 sampling campaign) in the Belgian farmland ponds. The table gives overall Pearson correlation coefficients of the pooled data of both years and significance levels between measures of biotic variables (phytoplankton biomass, genus richness and evenness as well as zooplankton biomass, species richness and evenness) and nine environmental variables (as presented in Appendix S1) and the biomasses of both trophic levels. Chl- $a$ and zooplankton biomass were logtransformed. Significance levels are $* * * p<.001, * * p<.01$ and $* p<.05 . N=76$ for all correlations, except for zooplankton evenness $(N=71)$. The graphs in Figure 1 depict the data for each year separately. Significant correlations are shown in bold for easier identification

\begin{tabular}{|c|c|c|c|c|c|c|c|c|c|c|c|}
\hline & TP & TN & Temp & Cond & $\mathrm{pH}$ & Area & Depth & Veget & Fish & Chl-a & ZPbiom \\
\hline \multicolumn{12}{|c|}{ Phytoplankton } \\
\hline Chl- $a$ & $0.44^{* * *}$ & $0.27^{*}$ & 0.05 & $0.45^{* * *}$ & $0.42^{* * *}$ & -0.07 & -0.22 & $-0.27^{*}$ & $0.30^{* *}$ & n.a. & -0.07 \\
\hline \multirow[t]{2}{*}{ Evenness } & -0.21 & -0.10 & -0.08 & $-0.26^{*}$ & -0.15 & 0.05 & 0.08 & $0.25^{*}$ & -0.15 & $-0.39^{* * *}$ & 0.00 \\
\hline & $\mathrm{TP}$ & $\mathrm{TN}$ & Temp & Cond & $\mathrm{pH}$ & Area & Depth & Veget & Fish & PP Rich & PP Even \\
\hline \multicolumn{12}{|l|}{ Zooplankton } \\
\hline Biomass & -0.12 & 0.00 & -0.07 & -0.16 & -0.04 & 0.07 & -0.14 & -0.16 & 0.11 & -0.07 & n.a. \\
\hline Richness & -0.03 & -0.05 & -0.01 & -0.07 & -0.04 & $0.25^{*}$ & 0.06 & -0.01 & 0.18 & -0.05 & -0.05 \\
\hline \multirow[t]{2}{*}{ Evenness } & -0.24 & -0.12 & -0.12 & -0.16 & -0.11 & -0.07 & 0.11 & 0.13 & -0.19 & $-0.32^{* *}$ & 0.05 \\
\hline & $\mathrm{TP}$ & $\mathrm{TN}$ & Temp & Cond & $\mathrm{pH}$ & Area & Depth & Veget & Fish & ZP Rich & ZP Even \\
\hline
\end{tabular}

correlation coefficients between variables across the two samplings, which indicate - if significant- - that the overall data set follows the same patterns.

All analyses were done in $\mathrm{R}$ ( $\mathrm{R}$ Development Core Team \& $\mathrm{R}$ Core Team 2013), using the packages psych (Revelle, 2013), vegan (Oksanen et al., 2013), MASS (Venables \& Ripley, 2002), ggbiplot, ggplot2 (Wickham, 2009), ggmap (Kahle \& Wickham, 2013), devtools, grid (R Development Core Team \& R Core Team 2013) and gridExtra (Auguie, 2012).

\section{3 | RESULTS}

\subsection{Basic patterns of environmental change in the ponds between 2003 and 2013}

Local environmental conditions differed strongly between ponds, but also significantly within ponds between years as was shown by applying variation partitioning analysis based on standardised RDA. "Year" significantly explained 5.3\% $(p<.001)$ of the variation in environmental variables, whereas "Pond Identity" explained $30 \%$ $(p<.001)$. The latter indicates that the selection of ponds was successful as they spanned the intended broad gradients in environmental conditions. The significant amount of variation explained by time indicates that the ponds underwent substantial environmental change, which allows addressing our hypotheses.

Our sensitivity analysis showed that across ponds and years, the biotic and abiotic variables followed well-known and consistent limnological patterns (Table 1, Figure 1). Phytoplankton biomass (Chl-a) increased with increasing TP as well as with conductivity, $\mathrm{pH}$ and nitrogen. Half of the ponds contained fish in 2003 (18/35). The overall reduction in fish presence in $2013(-50 \%)$ did not lead to a change in zooplankton biomass, but the expected cascading increase in phytoplankton biomass was found (Table 1) (Borer et al., 2005; Shurin et al., 2002). Phytoplankton biomass was further negatively correlated with total vegetation cover and pond depth (Table 1). Phytoplankton diversity declined with increasing TN (only richness) and increasing TP (both richness and evenness) and thus also with increasing standing biomass (Table 1, Figure 1). Higher genus richness was found in deeper ponds, higher evenness in ponds with larger vegetation cover. Zooplankton biomass and diversity indices did not significantly correlate to TP (Figure 1), but higher zooplankton richness appeared in larger ponds (surface area) and higher zooplankton evenness in ponds with higher amounts of phytoplankton biomass.

\section{2 | Overview of changes within the ponds between 2003 and 2013}

The overall amount of abiotic change and its variation was substantial across the 38 ponds (Appendix S3). A few variables showed consistent trends reflected by significant differences in LR from 0: TP significantly declined, whereas the depth and area of the ponds increased. Other variables showed substantial variation between ponds, but no consistent overall trend: LR for TN or conductivity indicated positive and negative changes by factor a $0.5-2$, and the fish presence was strongly reduced in 2013 (Appendix S3). Consequently, biotic variables showed even stronger magnitudes and variation in change between samplings. Phytoplankton biomass significantly declined $(\mathrm{LR}<0)$, whereas phytoplankton genus richness increased between the sampled years ( $L R>0$ ) (Appendix S3). Zooplankton biomass tended to decline between 2003 and 2013, but not generally across all ponds. Zooplankton evenness and RUE at both trophic levels showed broad variation in relative change (Appendix S3).

Community composition was almost entirely changed between 2003 and 2013 (Figure 2). In almost all ponds, the identity-based 

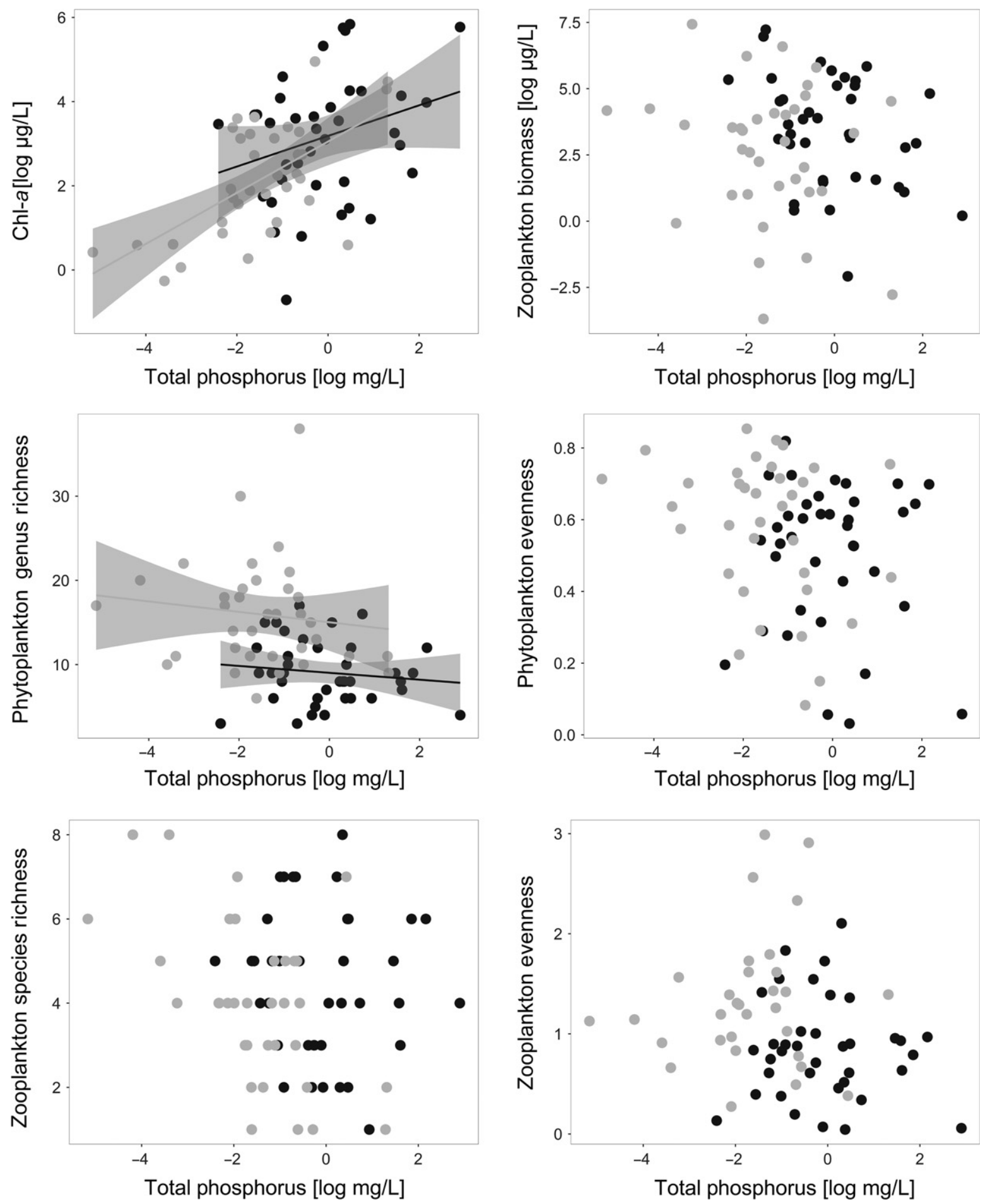

FIGURE 1 Algal and zooplankton biomass, richness and evenness correlated with total phosphorus (TP). Only the relationships between Chl- $a$ and phytoplankton genus richness with TP are significant (Table 2). Grey dots refer to results of the 2013 sampling campaign, black symbols to the results of the 2003 sampling campaign. Lines indicate significant relationships

Jaccard indices were $>0.8$ for both trophic levels, whereas the dominance-based Bray-Curtis indices were $>0.6$ for phytoplankton and mostly $>0.4$ for zooplankton. There was no significant correlation in the species turnover between the two trophic groups for either measure of dissimilarity, such that the magnitude of changes in phytoplankton composition and zooplankton composition were independent. When using Bray-Curtis distances, 9\% of the compositional variation in phytoplankton communities was due to systematic differences between Years (variation partitioning based on dbRDA, $p<.001$ ), whereas no variation could significantly be explained by Pond Identity (results remained similar when using the Jaccard distance: Year: $R^{2}$ adjusted: 4.2\%; $p<.001$; Pond Identity: $R^{2}$ adjusted: 
$0.1 \% ; p>.05)$. For zooplankton, using Bray-Curtis distances, Year and Pond Identity explained $2.5 \%$ and $9.2 \%$ of zooplankton compositional variation, respectively (both $p<.01$ ), whereas less variance was explained for Jaccard distances (Year 1.3\%; $p<.05$ and Pond Identity $3 \% ; p<.1)$.

\subsection{Correlation between environmental change and the change in biodiversity and species composition}

The first component of the standardised PCA performed on the combined environmental data of both years represents a nutrient gradient, alongside changes in conductivity, $\mathrm{pH}$ and fish presence. The second component is closely associated with variation in pond surface area (Figure 3, for details, see Appendix S2). Larger ponds tended to have less vegetation cover and deeper ponds seemed to be colder. The average change in environmental conditions between 2003 and 2013 and its variance indicated that a strong reduction in TP (LR $<0$, dependent $t$ test, $p<.01$ ) was opposed by increasing pond area (LR $>0$, dependent $t$ test, $p<.01)$ and depth $(\mathrm{LR}>0$, dependent $t$ test, $p<.05$ ) (Appendix S3).

The overall magnitude of change in environmental conditions (Dis$t_{E N V}$ ) was not significantly correlated to the measures of compositional turnover in phytoplankton or zooplankton (all correlations $p>.27$ for Bray-Curtis or Jaccard dissimilarity for both levels). For LR richness and LR evenness (Figure 4), only the change in phytoplankton evenness significantly increased with increasing environmental distance ( $r=.44, p=.008, N=35$ ), which encompassed a switch from positive to negative changes when the environmental variables changed more drastically. Although the correlation was not significant, the other LR for phyto- and zooplankton diversity measures also tended to be more positive in ponds with more substantial environmental change.

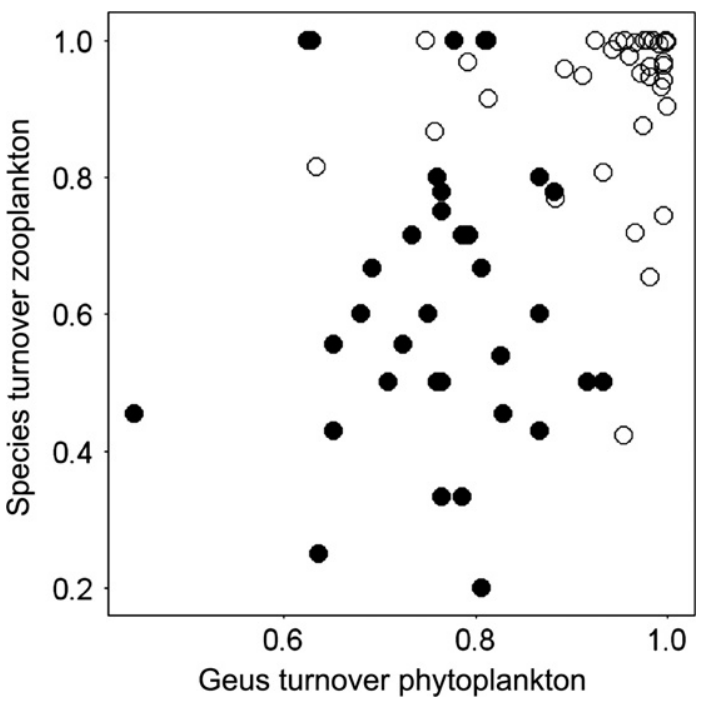

FIGURE 2 Dissimilarities of the zooplankton and phytoplankton communities of the individual ponds, based on the Bray-Curtis (black dots) and the Jaccard method (grey dots)
In the more resolved analyses, using the different environmental variables, we found that these could explain $17 \%-56 \%$ of the variance in biodiversity change across ponds (Table 2). Most substantial compositional changes were associated with the change in phytoplankton biomass: a stronger decrease in Chl-a concentration over time (more negative LR) was significantly related to a stronger increase (more positive LR) in phytoplankton evenness and richness, but to a decrease (negative LR) in zooplankton evenness (Figure 4, no relationship for zooplankton richness). Zooplankton evenness and richness increased more over time (positive LR) when TP decreased more, and zooplankton richness also increased more if zooplankton biomass decreased more (Table 2, see Appendix S4). Phytoplankton richness tended to increase more with a stronger increase in $\mathrm{pH}$ and TN (Appendix S4). Species turnover in phytoplankton was affected mainly by changes in morphometry, with larger changes in area (larger absolute LR) leading to almost full species turnover (Bray-Curtis). Species turnover in zooplankton was correlated positively to zooplankton biomass (Table 1), and increased, albeit non-significant, when changes in vegetation cover and TN were more pronounced (Table 1, Appendix S5).

\subsection{Correlation between environmental change and the change in RUE}

The magnitude of change in RUE was significantly correlated to the measure for overall environmental change (Dist $t_{E N V}$ ) for zooplankton (Pearson correlation, $p<.01$ ), but not for phytoplankton. Breaking down the analysis for single environmental variables, we found that $\mathrm{RUE}_{\mathrm{ZP}}$ was not significantly correlated with any of the environmental variables, whereas RUE $E_{P P}$ was significantly positively correlated with surface area $(p<.01)$ (Table 1$)$.

\subsection{Correlation between compositional change and the change in RUE}

Neither the change in $\mathrm{RUE}_{\mathrm{PP}}$ nor in $\mathrm{RUE}_{\mathrm{ZP}}$ was significantly related to measures of compositional turnover (Jaccard or Bray-Curtis, Figure 6). The correlations between LR RUE and LR richness and evenness were not significant for phytoplankton, but for zooplankton, the correlation between LR RUE highly significant $(p<.001)$ while the correlation between LR RUE ${ }_{Z P}$ and LR richness was marginally non-significant $(p<.07)$.

\section{4 | DISCUSSION}

Comparing data across ponds and between the sampling years 2003 and 2013 revealed a substantial spatial and temporal variation in abiotic variables, biotic composition, biomass and ecosystem function. It also revealed consistent correlations among variables that are well established in limnological literature, such as positive correlations of phytoplankton biomass to nutrient loading ( $P$ and $N$ ) (De Senerpont Domis, Van De Waal, Helmsing, Van Donk, \& Mooij, 2014; Hessen, Faafeng, Brettum, \& Andersen, 2006) and fish presence (Drenner, 

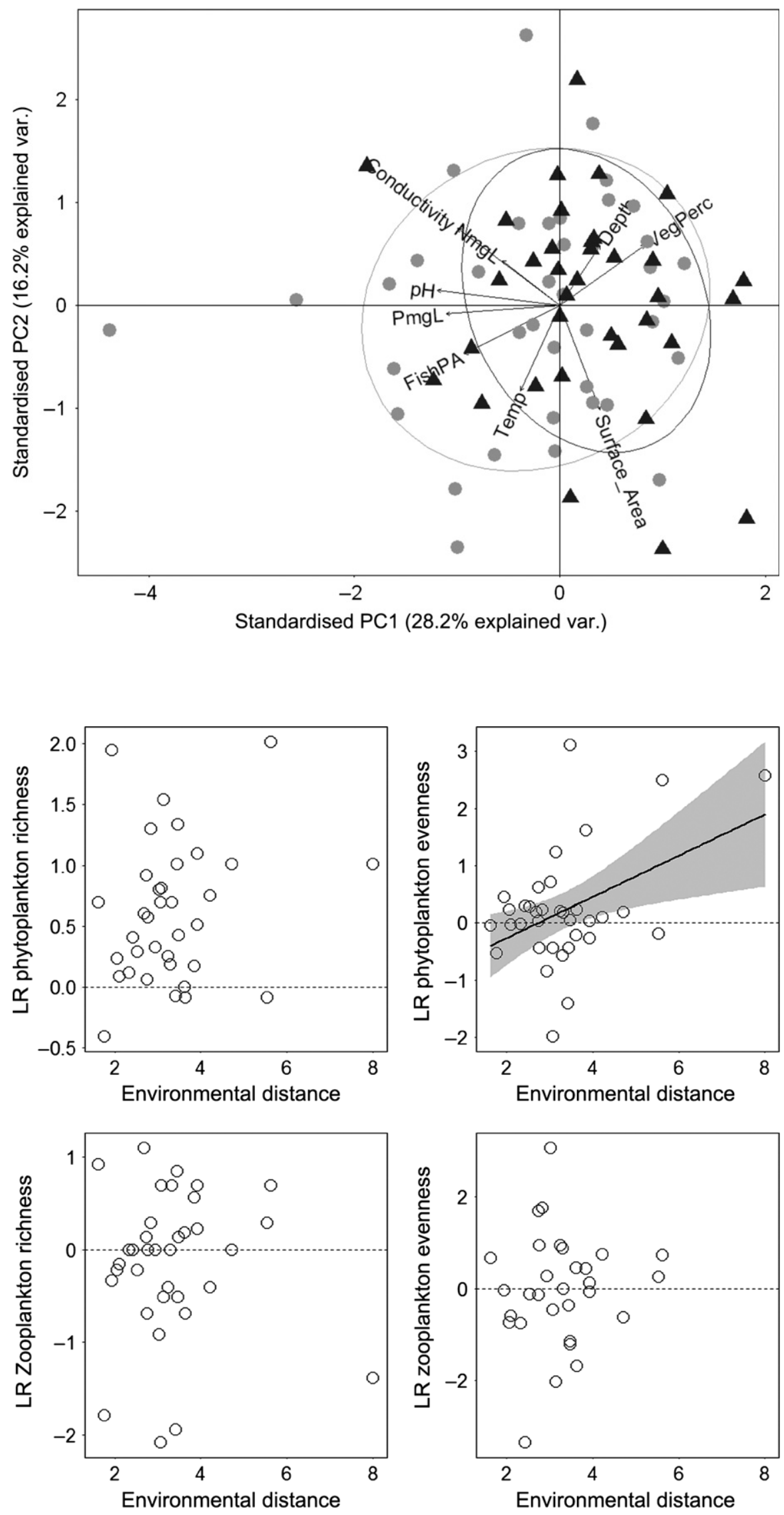

FIGURE 3 Standardised principal component analysis of the environmental conditions of all ponds. Black dots indicate ponds in 2003, triangles in 2013.

PmgL = total phosphorus in $\mathrm{mg} / \mathrm{L}$, $\mathrm{NmgL}=$ total nitrogen in $\mathrm{mg} / \mathrm{L}$, Conductivity $=$ conductivity in $\mu \mathrm{S} / \mathrm{cm}$, VegPerc $=$ percentage of surface area covered by vegetation, depth $=$ max. depth in metre, Temp $=$ temperature in ${ }^{\circ} \mathrm{C}$, FishPA $=$ fish presence/absence, $\mathrm{pH}=\mathrm{pH}$, Surface_Area $=$ surface area in $\mathrm{m}^{2}$

FIGURE 4 Change in species richness and evenness between 2013 and 2003 (expressed as log ratio; $0=$ no change) in correlation to the environmental distance (measured as Euclidean Distance between 2013 and 2003) in the respective ponds. Significant correlations $(p<.05)$ are indicated with a trendline 


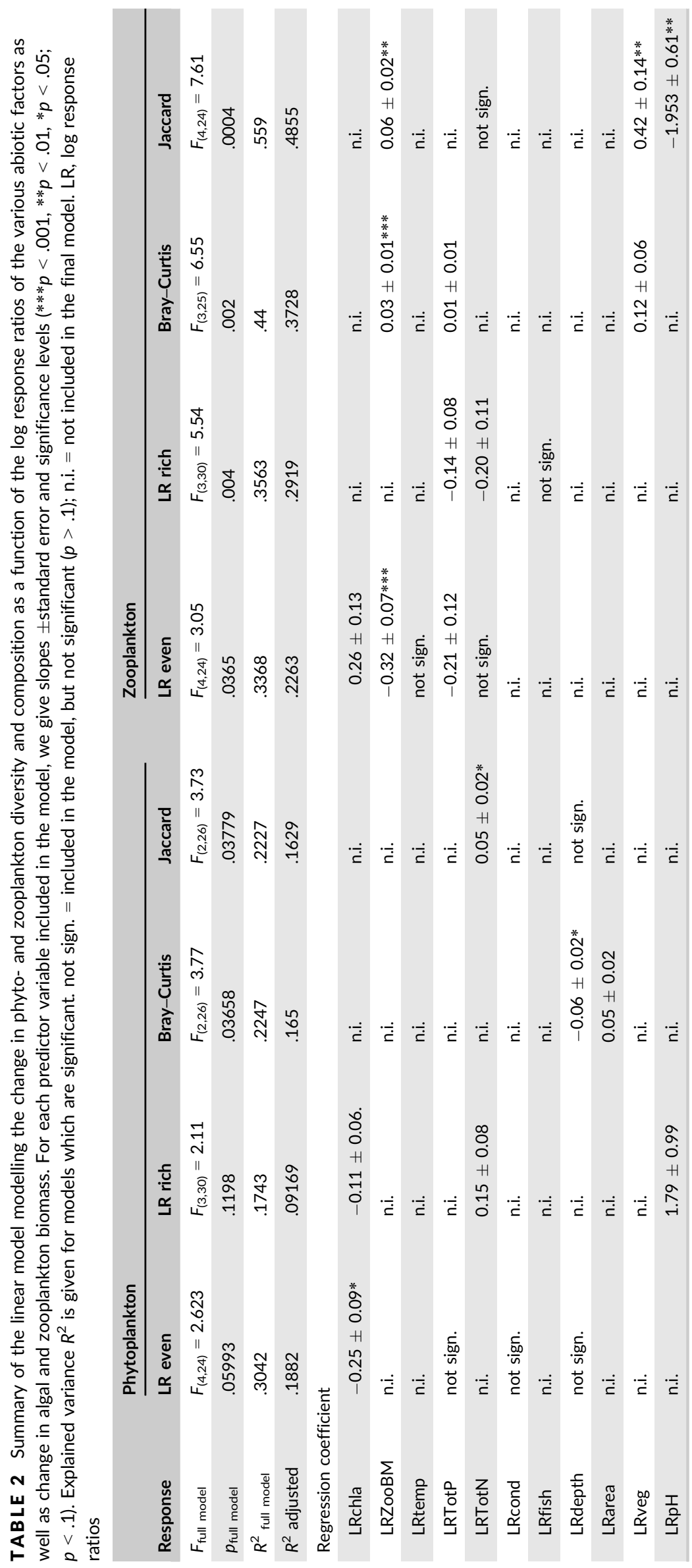


Gallo, Baca, \& Smith, 1998; Drenner, Threlkeld, Smith, Mummert, \& Cantrell, 1989), as well as negative correlations between the presence of macrophyte vegetation and phytoplankton biomass (Declerck, Vanderstukken, Pals, Muylaert, \& De Meester, 2007). More eutrophied ponds harboured less diverse and less even phyto- and zooplankton assemblages (compare Declerck et al., 2007; Jeppesen, Jensen, Sondergaard, Lauridsen, \& Landkildehus, 2000; Leibold, 1999). By contrast, deeper and larger ponds showed higher phyto- and zooplankton richness as predicted by species-area curves (Preston, 1960). The consistency of these patterns across samplings allows us to focus on the main questions regarding the relationship between the relative magnitude of change in the environment, the biota and the functions of these pond ecosystems between samplings. As we do not have information for the years between 2013 and 2003, our focus is on the relative magnitude of change (using multivariate techniques and log response ratios) between years. Irrespective of whether these changes reflect long-term temporal trends or only differences between these particular years, the overall qualitative consistency in the relationships between environmental variables and aspects of community biomass and biodiversity allows to discuss the differences in responses to the magnitude of environmental change.

\subsection{H1: A more intense change in environmental conditions over time leads to more intense changes in biotic composition}

The ponds differed in their individual environmental conditions (responsible for $30 \%$ of variance in variance partitioning), but also showed substantial change in environmental conditions over time $15 \%$ of variance). On average, TP was reduced by more than $70 \%$ between the sampling years 2003 and 2013, although most ponds were still in the eutrophic range (30-100 $\mu \mathrm{g} / \mathrm{L}$ TP, Lampert \& Sommer, 2007). Conversely, we observed no notable changes in the availability of nitrogen. This pattern is superficially congruent with a large-scale European trend in decreased nutrient loads through eutrophication mediation measures (Hartwich, Martin-Creuzburg, Rothhaupt, \& Wacker, 2012; Lindegren, Blenckner, \& Stenseth, 2012; Pomati, Matthews, Jokela, Schildknecht, \& Ibelings, 2012). However, the observed differences might also reflect inter-annual variation in weather conditions, most notably different precipitation levels. Indeed, during 2003 the ponds experienced an exceptionally dry summer, which resulted in partial drying, as is indicated by an average $32 \%$ reduction in depth and a $62 \%$ reduction in surface area compared to 2013 . This evaporation probably also resulted in the concentration of nutrients and may explain the higher P-content in 2003 compared to 2013. As TP decreased and TN remained unchanged during the considered period, the N:P ratio showed on average an increase. TP, depth, and surface area were the only significant environmental changes. An explanation why $\mathrm{P}$-levels decreased while $\mathrm{N}$-levels remained stable could be that nitrogen is more mobile than phosphorus and more easily washed from the sediment into the waterbodies (Peñuelas, Sardans, Rivasubach, \& Janssens, 2012; Peñuelas et al., 2013; Sardans, Rivas-Ubach, $\&$ Peñuelas, 2012).
Most likely, the decrease in TP and change in N:P ratio observed between 2003 and 2013 caused the large reductions in phytoplankton $(>75 \%)$ and zooplankton biomass $(>17 \%)$ and the corresponding changes in community composition. Still, the extent of turnover was still surprisingly high. Between 2003 and 2013, we observed 63\%$99 \%$ dissimilarity in phyto- and $42 \%-99 \%$ dissimilarity in zooplankton when including dominance aspects. Even on a presence-absence basis, on average $76 \%$ of the phytoplankton genera and $61 \%$ of the zooplankton species were replaced. Time accounted for only $9 \%$ of the total variation in composition, even though turnover at the individual pond level as very high. This reflects a large turnover also in space. As temporal turnover requires the presence of additional species in the species pool, the large spatial dissimilarity might explain why such strong turnover was possible.

By adjusting the level of identification to genus level in the phytoplankton and in some of the cladoceran genera, we avoided artefacts of different taxonomic identification by different experts in 2003 and 2013. The high compositional turnover observed here is thus a valid indicator of the high variability of small waterbodies (Scheffer et al., 2006). It is their size in particular that makes these ponds sensitive to environmental change in their immediate neighbourhood (Oertli et al., 2002): smaller size means less inertia so that even small changes in local environmental variables, such as nutrient load, can already profoundly affect these pond ecosystems (Heino, Virkkala, \& Toivonen, 2009; Rosset, Lehmann, \& Oertli, 2010). This sensitivity was proposed to make pond systems vulnerable to disturbances and, ultimately, to regime shifts (Scheffer, 1989; Scheffer \& Van Nes, 2007), but lacking data on intermediate years we were not able to test this explicitly.

Change in phytoplankton diversity increased with greater environmental change (calculated as Euclidean distance, that is a measure that combines all abiotic factors considered into one value of change), partly accepting H1. No such pattern could be found for zooplankton (see below). Furthermore, the species turnover rates of both trophic levels did not correlate, partly refuting $\mathrm{H} 1$. The increase in phytoplankton richness with greater environmental change suggested that phytoplankton diversity benefited strongly from oligotrophication and area increase between 2003 and 2013, which were the key aspects of environmental change. The reduction in Chl- $a$ (phytoplankton biomass) was the best predictor for increasing evenness of phytoplankton. A reduction in evenness with increased biomass is a very common finding for autotrophs in all ecosystems such that our results are in line with expectations from experimental studies on fertilisation (Hillebrand et al., 2007), especially given the high values of TP we have in the ponds studied (range 0.005$18.16 \mathrm{mg} / \mathrm{L}$, mean value $1.26 \mathrm{mg} / \mathrm{L}$ ). The reduction in nutrient concentrations resulted in increased phytoplankton richness as well, potentially because less dominance of highly productive species allowed more species to coexist due to the absence of strong competitive exclusion (Jeppesen et al., 2005; Pomati et al., 2012). Opposed to phytoplankton, zooplankton diversity (richness and evenness) reacted negatively to nutrient decreases. Zooplankton evenness increased with higher Chl-a (food quantity) availability, but decreased with zooplankton biomass, which reflects a shift in 
FIGURE 5 Log response ratios (LR) of richness and evenness for the phytoplankton and zooplankton communities plotted against the log response ratio of Chl- $a$ as a measure for change in productivity. Significant $(p<.05)$ correlations are indicated with a trendline. Negative LR mean that the values were higher in 2003 than in 2013 (overall decrease), and positive values mean values were higher in 2013 than in 2003 (overall increase)
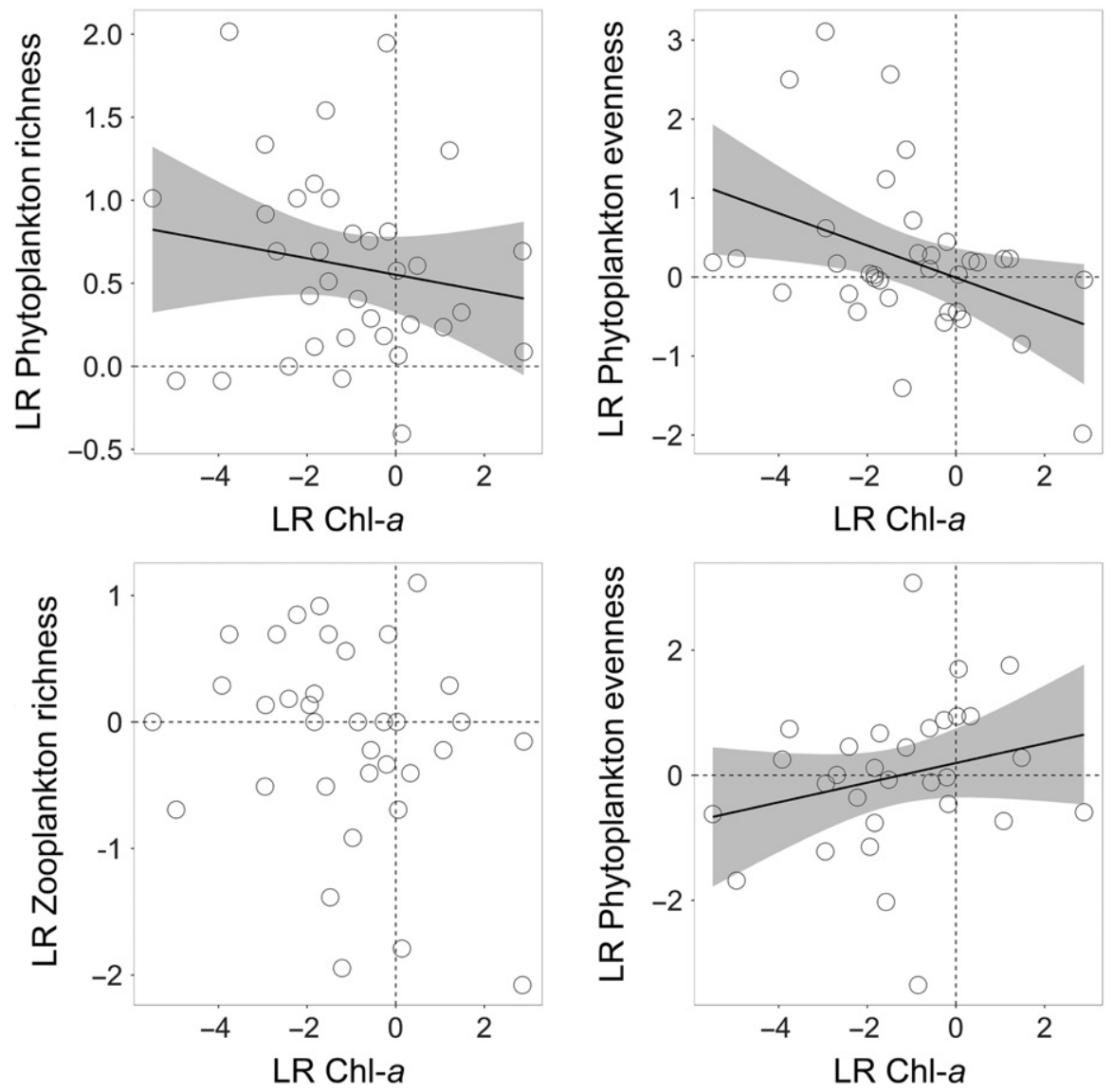

composition from a more diverse community of smaller species towards fewer and larger species with greater resource requirements.

\subsection{H2a: The magnitude of functional change increases with larger environmental change}

Overall, the change in RUE across all ponds showed great variation. Phytoplankton is not homoeostatic, that is can vary in its stoichiometry dependent on the availability of resources in the environment to a certain degree (Sterner \& Elser, 2002). Given this, we would have expected an increase in RUE following oligotrophication, as the same amount of biomass could have been produced on a lower amount of phosphorous. However, neither total environmental change nor community turnover had a significant effect in phytoplankton RUE. The recorded lack of change coincided with a decrease in Chl-a together with a decrease in phosphorus (Figure 1).

\subsection{H2b: The magnitude of functional change correlates negatively (redundancy) or positively (loss of functionally important species) with compositional turnover}

Following the positive relationship between RUE and diversity found for phytoplankton (Ptacnik et al., 2008), we would have expected an increase in RUE with the increase in phytoplankton richness but could not find any significant correlation between the two measures. However, it has also been shown that there is a strong inverse relationship between evenness and phytoplankton biomass and RUE (Filstrup et al., 2014; Hodapp, Meier, Muijsers, Badewien, \& Hillebrand, 2015; Lehtinen, Tamminen, Ptacnik, \& Andersen, 2017). In this study, we found a significant positive relationship between phytoplankton evenness and total environmental change (Figure 5), which could therefore be the underlying cause why the RUE did not change significantly with nutrient supply. With a simultaneous decrease in biomass production and resource availability, RUE should not vary much, even if the two factors from which the ratio is calculated are affected by different mechanisms. In this case, the potential increase in RUE with oligotrophication was counteracted by a decrease with increasing phytoplankton evenness.

The change in RUE of zooplankton was not related to species turnover but increased significantly with greater environmental change (Figure 6), indicating strong environmental effects on higher trophic levels. Given that nutrient limitation for phytoplankton also reduces its food quality for zooplankton (Elser, Hayakawa, \& Urabe, 2001), the fact that nevertheless RUE did not decrease indicates a shift towards species with higher efficiency. Based on findings by Gliwicz (1990) that show higher growth rates of largerbodied zooplankton at low food concentrations, we would expect an increase in RUE with decrease in resource availability (in this case $\mathrm{Chl}-a$ ). 


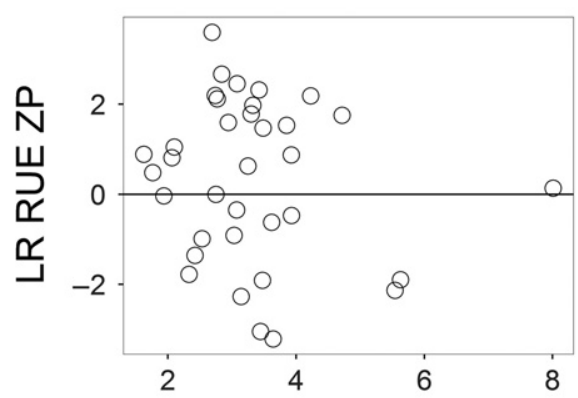

Environmental distance
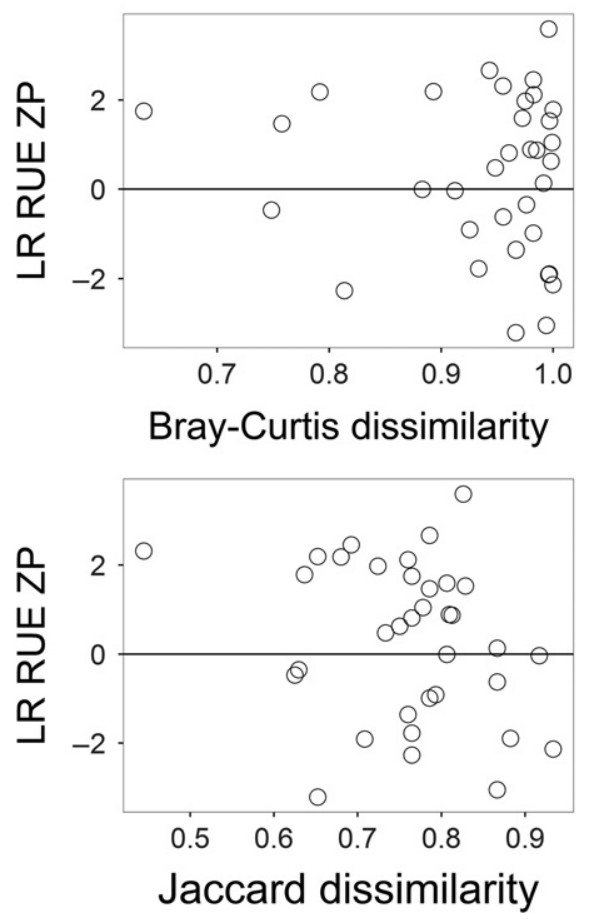

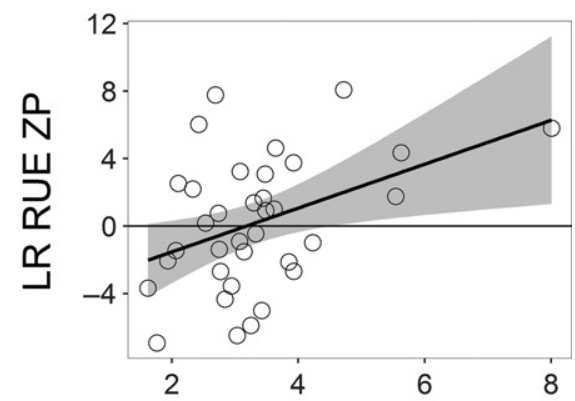

Environmental distance
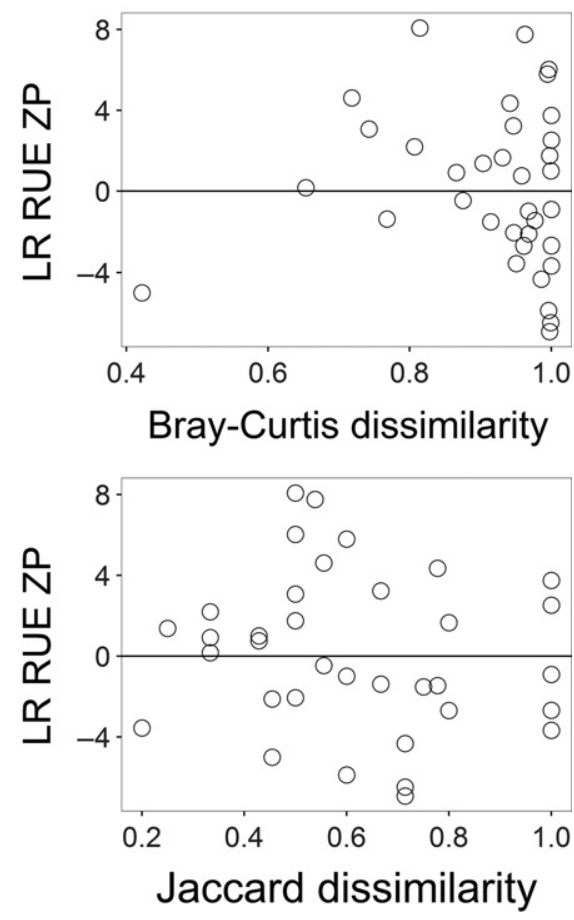

FIGURE 6 Change in resource use efficiency of phytoplankton (PP) and zooplankton (ZP) (measured as log response ratio, LR RUE PP or LR RUE ZP, respectively) related to environmental distance (measured as Euclidean distance), Bray-Curtis and Jaccard dissimilarity. Significant $(p<.05)$ correlations are indicated with a trendline
As most ponds tended to decrease in phytoplankton biomass (Appendix S2), the change in zooplankton RUE might have been caused by a compositional shift towards larger species. Indeed, we found a shift from communities mainly dominated by Bosmina and Chydorus species to ones with greater abundances of Alona, Daphnia and Simocephalus with oligrotrophication, although Bosmina was still the most abundant, which makes them highly relevant to ecosystem function performance (Winfree, Fox, Williams, Reilly, \& Cariveau, 2015).

Both, the increase in evenness and therefore niche partitioning and the shift towards larger species, an overall increase in RUE of zooplankton was expected (Ye, Chang, García-Comas, Gong, \& Hsieh, 2013). In terms of biomass, there was strong increase in biomass of Daphnia, similar to the shift in abundance (Appendix S6). Both these changes were mainly driven by larger populations of Daphnia magna and Daphnia longispina (data not shown), which is relevant given the size differences in Daphnia species and therefore differences in growth rates and RUE (Tessier, Leibold, \& Tsao, 2000). The shift towards higher evenness and larger species ultimately points to a more top-down controlled community of plankton (Gianuca, Pantel, \& De Meester, 2016; Ye et al., 2013), as opposed to a highly eutrophic, bottom-up controlled one.
Possibly due to the very high variation between the different ponds investigated, we did not find any correlation between zooplankton RUE and community change (both dissimilarity measures, Figure 6). The increase in both evenness and RUE could also be due to complimentary resource niches (Norberg, 2000). Another possibility would be that high zooplankton RUE was maintained by subsidy from the consumption of alternative food sources, such as detritus or bacteria, to achieve the necessary ratio of consumed nutrients, but such a subsidy effect would be more likely the case with increasing eutrophication, not oligotrophication. Unfortunately, we have no data to disentangle these alternatives.

\section{4 | H3: Responses to environmental change in terms of composition and function differ across trophic levels}

The two trophic levels investigated reacted differently to the overall change in the environmental factors (accepting H3). While the change in phytoplankton evenness significantly correlated with total environmental change, we could not find any such pattern for the zooplankton community. Neither species richness nor evenness changes in 
zooplankton had any directional trend that could be related to the overall environmental change. This reflects the fact that the main changes in the ponds showed opposite effects on the change in evenness for zooplankton (Table 1): zooplankton evenness increased over time when phytoplankton biomass increased or stayed constant (Figure 4), but zooplankton evenness decreased if TP and zooplankton biomass stayed high (Appendix S3). Thus, the most important aspect of environmental change, the decrease in TP, had countercurrent effects on zooplankton diversity. Related to the overall decrease in nutrient concentrations across ponds (negative LR TP), we observed a decrease in biomass through primary production (negative LR Chl-a), and this decrease in prey biomass might have triggered a decrease in zooplankton diversity through limited resource availability (Table 1). The observed inverse effects (increased phytoplankton biomass decreases phytoplankton richness and evenness, but increases zooplankton evenness) can be explained as the result of competitive dominance associated with biomass production at both levels. Similarly, Declerck et al. (2005) found in their pond assessment that different trophic groups, including phyto- and zooplankton, react differently or even opposing to single environmental gradients such as TP. Phytoplankton evenness was low at high Chl- $a$ concentrations, but in turn, higher primary production can increase zooplankton biomass (McCauley \& Kalff, 1996) and diversity as predicted by, for example, the species-energy theory (Brown, Gillooly, Allen, Savage, \& West, 2004). Corroborating this idea, Declerck et al. (2007) found that increasing phosphorus loads and an increase in phytoplankton biomass lead to a decline in zooplankton richness, as the best-suited predator became dominant. In both cases, an increase in biomass comes with a decrease in diversity of the respective trophic level.

\section{5 | CONCLUSIONS}

Even though there are pronounced local differences between the individual ponds, we were able to show overarching patterns of change and response across two sampling campaigns separated by a decade. There was a strong environmental change regarding nutrient content and morphometry, which can be driven by long-term trends or differences in precipitation. Irrespective of the source of environmental change, we found that changes in environmental characteristics translate into changes in plankton communities. Strong reductions in TP resulted in strong biomass decrease at both trophic levels, and in a strong increase in phytoplankton richness and evenness. The consequences for zooplankton richness and evenness were mixed, reflecting countercurrent effects of prey biomass reduction and zooplankton biomass reduction. There was a nearly complete species turnover in both phyto- and zooplankton in most ponds. However, the change in RUE was overall slightly positive, which indicates a shift towards more efficient species in the light of oligotrophication (phytoplankton), while zooplankton evenness decreased with lower food quantity.

Our results point to strong effects of variation in year-specific weather conditions, which might become more severe according to climate change predictions (Rosenzweig et al., 2007), in particular regarding precipitation (Trenberth, 2011). While much scientific investigation focuses on eutrophication, with increasing success in management efforts to reduce anthropogenic input of phosphorus and nitrogen, it has also become necessary to consider the effects of oligotrophication on plankton communities and higher trophic levels. The opposing trends for zooplankton and phytoplankton communities indicate that environmental changes act as different stressors for different trophic levels. There is a need for more insight on how the interactive effects of weather conditions and nutrient concentrations impact year-to-year variation in the functioning of aquatic systems.

\section{ACKNOWLEDGMENTS}

We would like to thank Heike Rickels and Silke Ammermann at the University of Oldenburg for help with sample analysis. We thank Tom De Bie and co-workers for their work done for the original data set. This research was funded by the ERA-Net BiodivERsA, with the national funders BMBF (Germany) and Belspo (Belgium), part of the 2012 BiodivERsA call for research proposals. ATG and FTTH received full PhD scholarships from Brazil under the programme "Science Without Borders - CNPq" (grant numbers 245629/2012-2 and 245968/ 2012-1, respectively).

\section{CONFLICT OF INTEREST}

The authors have no conflict of interest to declare.

\section{ORCID}

Laura Verbeek iD http://orcid.org/0000-0002-1488-6522

\section{REFERENCES}

Adrian, R., Reilly, C. M. O., Zagarese, H., Baines, S. B., Hessen, D. O., Keller, W., ... Winder, M. (2009). Lakes as sentinels of climate change. Limnology and Oceanography, 54, 2283-2297. https://doi.org/10. 4319/lo.2009.54.6_part_2.2283

Auguie, B. (2012). gridExtra: Functions in Grid graphics.

Borer, A. E. T., Seabloom, E. W., Shurin, J. B., Anderson, K. E., Blanchette, C. A., Broitman, B., ... Halpern, B. S. (2005). What determines the strength of a trophic cascade? Ecology, 86, 528-537. https://doi.org/ 10.1890/03-0816

Bray, J. R., \& Curtis, J. T. (1957). An ordination of the upland forest communities of Southern Wisconsin. Ecological Monographs, 27, 325-349.

Bottrell, H. H. (1976). A review of some problems in zooplankton production studies. Norwegian Journal of Zoology, 24, 419-456.

Brown, J. H., Gillooly, J. F., Allen, A. P., Savage, V. M., \& West, G. B. (2004). Toward a metabolic theory of ecology. Ecolgy, 85, 17711789. https://doi.org/10.1890/03-9000

Burnham, K. P., \& Anderson, D. R. (2002). Model selection and multimodel inference: A practical information-theoretic approach, 2nd ed. New York: Springer.

Cardinale, B. J., Bennett, D. M., Nelson, C. E., \& Gross, K. (2009). Does productivity drive diversity or vice versa? A test of the multivariate 
productivity-diversity hypothesis in streams. Ecology, 90, 1227-1241. https://doi.org/10.1890/08-1038.1

Céréghino, R., Biggs, J., Oertli, B., \& Declerck, S. (2008). The ecology of European ponds: Defining the characteristics of a neglected freshwater habitat. Hydrobiologia, 597, 1-6. https://doi.org/10.1007/s10750007-9225-8

Céréghino, R., Boix, D., Cauchie, H.-M., Martens, K., \& Oertli, B. (2014). The ecological role of ponds in a changing world. Hydrobiologia, 723, 1-6. https://doi.org/10.1007/s10750-013-1719-y

Cottingham, K. L., Brown, B. L., \& Lennon, J. T. (2001). Biodiversity may regulate the temporal variability of ecological systems. Ecology Letters, 4, 72-85. https://doi.org/10.1046/j.1461-0248.2001.00189.x

De Bie, T., De Meester, L., Brendonck, L., Martens, K., Goddeeris, B., Ercken, D., ... Declerck, S. A. (2012). Body size and dispersal mode as key traits determining metacommunity structure of aquatic organisms. Ecology Letters, 15, 740-747. https://doi.org/10.1111/j.14610248.2012.01794.x

De Meester, L., Declerck, S., Stoks, R., Louette, G., Van De Meutter, F., De Bie, T., ... Brendonck, L. (2005). Ponds and pools as model systems in conservation biology, ecology and evolutionary biology. Aquatic Conservation: Marine and Freshwater Ecosystems, 15, 715-725. https://doi.org/10.1002/(ISSN)1099-0755

De Senerpont Domis, L. N., Van De Waal, D. B., Helmsing, N. R., Van Donk, E., \& Mooij, W. M. (2014). Community stoichiometry in a changing world: Combined effects of warming and eutrophication on phytoplankton dynamics. Ecology, 95, 1485-1495. https://doi.org/10. 1890/13-1251.1

Declerck, S., De Bie, T., Ercken, D., Hampel, H., Schrijvers, S., Van Wichelen, J., ... Martens, K. (2006). Ecological characteristics of small farmland ponds: Associations with land use practices at multiple spatial scales. Biological Conservation, 131, 523-532. https://doi.org/10. 1016/j.biocon.2006.02.024

Declerck, S., Vandekerkhove, J., Johansson, L., Muylaert, K., Conde-Porcuna, J. M., Van Der Gucht, K., ... De Meester, L. (2005). Multi-group biodiversity in shallow lakes along gradients of phosphorous and water plant cover. Ecology, 86, 1905-1915. https://doi.org/10.1890/ 04-0373

Declerck, S., Vanderstukken, M., Pals, A., Muylaert, K., \& De Meester, L. (2007). Plankton biodiversity along a gradient of productivity and its mediation by macrophytes. Ecology, 88, 2199-2210. https://doi.org/ 10.1890/07-0048.1

Dornelas, M., Gotelli, N. J., McGill, B., Shimadzu, H., Moyes, F., Sievers, C., \& Magurran, A. E. (2014). Assemblage time series reveal biodiversity change but not systematic loss. Science (New York, N.Y.), 344, 296-299.

Drenner, R. W., Gallo, K. L., Baca, R. M., \& Smith, J. D. (1998). Synergistic effects of nutrient loading and omnivorous fish on phytoplankton biomass. Canadian Journal of Fisheries and Aquatic Sciences, 55, 2087 2096. https://doi.org/10.1139/f98-095

Drenner, R. W., Threlkeld, S. T., Smith, J. D., Mummert, J. R., \& Cantrell, P. A. (1989). Interdependence of phosphorus, fish, and site effects on phytoplankton biomass and zooplankton. Limnology and Oceanography, 34, 1315-1321. https://doi.org/10.4319/lo.1989.34.7.1315

Dumont, H. J., Van de Velde, I., \& Dumont, S. (1975). The dry weight estimate of biomass in a selection of Cladocera, Copepoda and Rotifera from the plankton, periphyton and benthos of continental waters. Oecologia, 19, 75-97. https://doi.org/10.1007/BF00377592

Elser, J. J., Fagan, W. F., Denno, R. F., Dobberfuhl, D. R., Folarin, A., Huberty, A., ... Sterner, R. W. (2000). Nutritional constraints in terrestrial and freshwater food webs. Nature, 408, 578-580. https://doi.org/10. 1038/35046058

Elser, J. J., Hayakawa, K., \& Urabe, J. (2001). Nutrient limitation reduces food quality for zooplankton: Daphnia response to seston phosphorus enrichment. Ecology, 82, 898-903. https://doi.org/10.1890/00129658(2001)082[0898:NLRFQF]2.0.CO;2
Filstrup, C. T., Hillebrand, H., Heathcote, A. J., Harpole, W. S., \& Downing, J. A. (2014). Cyanobacteria dominance influences resource use efficiency and community turnover in phytoplankton and zooplankton communities. Ecology Letters, 17, 464 474. https://doi.org/10.1111/ele.12246

Flössner, D. (2000). Die Haplopoda und Cladocera (ohne Bosminidae) Mitteleuropas. Leiden, Germany: Backhuys.

Gianuca, A. T., Pantel, J. H., \& De Meester, L. (2016). Disentangling the effect of body size and phylogenetic distances on zooplankton topdown control of algae. Proceedings of the Royal Society B: Biological Sciences, 283, pii: 20160487.

Gliwicz, Z. M. (1990). Food thresholds and body size in cladocerans. Nature, 343, 638-640. https://doi.org/10.1038/343638a0

Grasshoff, K., Kremling, K., \& Ehrhardt, M. (2007). Methods of seawater analysis, 3rd ed. In K. Grasshoff, K. Kremling, \& M. Ehrhardt (Eds.). Weinheim, Germany: Wiley-VCH.

Hartwich, M., Martin-Creuzburg, D., Rothhaupt, K. O., \& Wacker, A. (2012). Oligotrophication of a large, deep lake alters food quantity and quality constraints at the primary producer-consumer interface. Oikos, 121, 1702-1712. https://doi.org/10.1111/j.1600-0706.2011.20461.x

Heino, J., Virkkala, R., \& Toivonen, H. (2009). Climate change and freshwater biodiversity: Detected patterns, future trends and adaptations in northern regions. Biological Reviews, 84, 39-54. https://doi.org/10. 1111/j.1469-185X.2008.00060.x

Hessen, D. O., Faafeng, B. A., Brettum, P., \& Andersen, T. (2006). Nutrient enrichment and planktonic biomass ratios in lakes. Ecosystems, 9, 516-527. https://doi.org/10.1007/s10021-005-0114-6

Hillebrand, H., Bennett, D. M., \& Cadotte, M. W. (2008). Consequences of dominance: A review of evenness effects on local and regional ecosystem processes. Ecology, 89, 1510-1520. https://doi.org/10. 1890/07-1053.1

Hillebrand, H., Blasius, B., Borer, E. T., Chase, J. M., Downing, J. A., Eriksson, B. K., ... Ryabov, A. B. (2017). Biodiversity change is uncoupled from species richness trends: Consequences for conservation and monitoring. Journal of Applied Ecology, 55, 169-184.

Hillebrand, H., Gruner, D. S., Borer, E. T., Bracken, M. E. S., Cleland, E. E., Elser, J. J., ... Smith, J. E. (2007). Consumer versus resource control of producer diversity depends on ecosystem type and producer community structure. Proceedings of the National Academy of Sciences of the United States of America, 104, 10904-9. https://doi.org/10.1073/ pnas. 0701918104

Hillebrand, H., \& Matthiessen, B. (2009). Biodiversity in a complex world: Consolidation and progress in functional biodiversity research. Ecology Letters, 12, 1405-1419. https://doi.org/10.1111/j.1461-0248. 2009.01388.x

Hodapp, D., Meier, S., Muijsers, F., Badewien, T. H., \& Hillebrand, H. (2015). Structural equation modeling approach to the diversity-productivity relationship of Wadden Sea phytoplankton. Marine Ecology Progress Series, 523, 31-40. https://doi.org/10.3354/meps11153

Jaccard, P. (1912). The distribution of the flora in the alphine zone. New Phytologist, XI, 37-50.

Jeppesen, E., Jensen, J. P., Sondergaard, M., Lauridsen, T., \& Landkildehus, F. (2000). Trophic structure, species richness and biodiversity in Danish lakes: Changes along a phosphorus gradient. Freshwater Biology, 45, 201-218. https://doi.org/10.1046/j.1365-2427.2000.00675.x

Jeppesen, E., Søndergaard, M., Jensen, J. P., Havens, K. E., Anneville, O., Carvalho, L., ... Winder, M. (2005). Lake responses to reduced nutrient loading - An analysis of contemporary long-term data from 35 case studies. Freshwater Biology, 50, 1747-1771. https://doi.org/10. 1111/j.1365-2427.2005.01415.x

Kahle, D., \& Wickham, H. (2013). ggmap: Spatial Visualization with ggplot2. The R Journal, 5, 144-161.

Lampert, W., \& Sommer, U. (2007). Limnoecology: The ecology of lakes and streams. Oxford, UK: OUP.

Lehtinen, S., Tamminen, T., Ptacnik, R., \& Andersen, T. (2017). Phytoplankton species richness, evenness, and production in relation to 
nutrient availability and imbalance. Limnology and Oceanography, 62, 1393-1408. https://doi.org/10.1002/Ino.10506

Leibold, M. A. (1999). Biodiversity and nutirent enrichment in pond plankton communities. Evolutionary Ecology Research, 1, 73-95.

Lindegren, M., Blenckner, T., \& Stenseth, N. C. (2012). Nutrient reduction and climate change cause a potential shift from pelagic to benthic pathways in a eutrophic marine ecosystem. Global Change Biology, 18, 3491-3503. https://doi.org/10.1111/j.1365-2486.2012.02799.x

Louette, G., \& De Meester, L. (2005). High dispersal capacity of cladoceran zooplankton in newly founded communities. Ecology, 86, 353359. https://doi.org/10.1890/04-0403

McCauley, E., \& Kalff, J. (1996). Empirical relationships between phytoplankton and zooplankton biomass in lakes. Canadian Journal of Fisheries and Aquatic Sciences, 38, 458-463.

Millenium Ecosystem Assessment (2010). Ecosystems and human wellbeing: Biodiversity synthesis. Washington D.C.: World Resources Institute.

Mittelbach, G. G., Steiner, C. F., Scheiner, S. M., Gross, K. L., Reynolds, H. L., Waide, R. B., ... Gough, L. (2001). What is the observed relationship between species richness and productivity? Ecology, 89, 23812396. https://doi.org/10.1890/0012-9658(2001)082[2381:WITORB] 2.0.CO;2

Norberg, J. (2000). Resource-niche complementarity and autotrophic compensation determines ecosystem-level responses to increased cladoceran species richness. Oecologia, 122, 264-272. https://doi. org/10.1007/PL00008855

Oertli, B., Joye, D. A., Castella, E., Juge, R., Cambin, D., \& Lachavanne, J. B. (2002). Does size matter? The relationship between pond area and biodiversity. Biological Conservation, 104, 59-70. https://doi.org/10. 1016/S0006-3207(01)00154-9

Oksanen, J., Blanchet, F. G., Kindt, R., Legendre, P., Minchin, P. R., O'Hara, R. B., ... Wagner, H. (2013). vegan: Community ecology package.

Peñuelas, J., Poulter, B., Sardans, J., Ciais, P., van der Velde, M., Bopp, L., ... Janssens, I. A. (2013). Human-induced nitrogen-phosphorus imbalances alter natural and managed ecosystems across the globe. Nature Communications, 4, 2934.

Peñuelas, J., Sardans, J., Rivas-ubach, A., \& Janssens, I. A. (2012). The human-induced imbalance between $\mathrm{C}, \mathrm{N}$ and $\mathrm{P}$ in Earth's life system. Global Change Biology, 18, 3-6. https://doi.org/10.1111/j.1365-2486. 2011.02568.x

Pielou, E. C. (1966). The measurement of diversity in different types of biological collections. Journal of Theoretical Biology, 13, 131-144. https://doi.org/10.1016/0022-5193(66)90013-0

Pomati, F., Matthews, B., Jokela, J., Schildknecht, A., \& Ibelings, B. W. (2012). Effects of re-oligotrophication and climate warming on plankton richness and community stability in a deep mesotrophic lake. Oikos, 121, 1317-1327. https://doi.org/10.1111/j.1600-0706.2011. 20055.x

Preston, F. W. (1960). Time and space and the variation of species. Ecology, 41, 612-627.

Ptacnik, R., Solimini, A. G., Andersen, T., Tamminen, T., Brettum, P., Lepistö, L., ... Rekolainen, S. (2008). Diversity predicts stability and resource use efficiency in natural phytoplankton communities. Proceedings of the National Academy of Sciences of the United States of America, 105, 5134-8. https://doi.org/10.1073/pnas. 0708328105

R Development Core Team \& R Core Team (2013). R: A language and environment for statistical computing. Vienna, Austria: $\mathrm{R}$ Foundation for Statistical Computing. Retrieved from http://www.R-project.org/

Redfern, J. V., Grant, C. C., Gaylard, A., \& Getz, W. M. (2005). Surface water availability and the management of herbivore distributions in an African savanna ecosystem. Journal of Arid Environments, 63, 406424. https://doi.org/10.1016/j.jaridenv.2005.03.016

Reiss, J., Bridle, J. R., Montoya, J. M., \& Woodward, G. (2009). Emerging horizons in biodiversity and ecosystem functioning research. Trends in Ecology \& Evolution, 24, 505-514. https://doi.org/10.1016/j.tree. 2009.03.018

Revelle, W. (2013). psych: Procedures for psychological, psychometric, and personality research. Evanston, Illinois: Northwestern University.

Rosenzweig, C., Casassa, G., Karoly, D. J., Imeson, A., Germany, A. M., Menzel, A., ... Tryjanowski, P. (2007). Assessment of observed changes and responses in natural and managed systems. In $\mathrm{M}$. L. Parry, O. F. Canziani, J. P. Palutikof, P. J. van der Linden, \& C. E. Hanson (Eds.), Climate Change 2007: Impacts, Adaptation and Vulnerability. Contribution of Working Group II to the Fourth Assessment Report of the Intergovernmental Panel on Climate Change (pp. 79-131). Cambridge, U.K.: Cambridge University Press.

Rosset, V., Lehmann, A., \& Oertli, B. (2010). Warmer and richer? Predicting the impact of climate warming on species richness in small temperate waterbodies. Global Change Biology, 16, 2376-2387. https:// doi.org/10.1111/j.1365-2486.2010.02206.x

Sardans, J., Rivas-Ubach, A., \& Peñuelas, J. (2012). The C:N:P stoichiometry of organisms and ecosystems in a changing world: A review and perspectives. Perspectives in Plant Ecology, Evolution and Systematics, 14, 33-47. https://doi.org/10.1016/j.ppees.2011.08.002

Scheffer, M. (1989). Alternative stable states in eutrophic, shallow freshwater systems: A minimal model. Hydrobiological Bulletin, 23, 73-83. https://doi.org/10.1007/BF02286429

Scheffer, M., \& Carpenter, S. R. (2003). Catastrophic regime shifts in ecosystems: Linking theory to observation. Trends in Ecology and Evolution, 18, 648-656.

Scheffer, M., Hosper, S. H., Meijer, M. L., Moss, B., \& Jeppesen, E. (1993). Alternative equilibria in shallow lakes. Trends in Ecology \& Evolution, 8, 275-279. https://doi.org/10.1016/0169-5347(93)90254-M

Scheffer, M., Van Geest, G. J., Zimmer, K., Jeppesen, E., Søndergaard, M., Butler, M. G., ... De Meester, L. (2006). Small habitat size and isolation can promote species richness: Second-order effects on biodiversity in shallow lakes and ponds. Oikos, 112, 227-231. https://doi.org/ 10.1111/j.0030-1299.2006.14145.x

Scheffer, M., \& Van Nes, E. H. (2007). Shallow lakes theory revisited: Various alternative regimes driven by climate, nutrients, depth and lake size. Hydrobiologia, 584, 455-466. https://doi.org/10.1007/ s10750-007-0616-7

Shurin, J. B., Borer, E. T., Seabloom, E. W., Anderson, K., Blanchette, C. A., Broitman, B., ... Halpern, B. S. (2002). A cross ecosystem comparison of the strength of trophic cascades. Ecology Letters, 5, 785-791.

Sterner, R. W. (2008). On the phosphorus limitation paradigm for lakes. International Review of Hydrobiology, 93, 433-445. https://doi.org/10. 1002/iroh.200811068

Sterner, R. W., \& Elser, J. J. (2002). Ecological stoichiometry: The biology of elements from molecules to the biosphere. Princeton, NJ: Princeton University Press.

Striebel, M., Singer, G., Stibor, H., \& Andersen, T. (2012). "Trophic overyielding": Phytoplankton diversity promotes zooplankton productivity. Ecology, 93, 2719-2727. https://doi.org/10.1890/12-0003.1

Suding, K. N., Lavorel, S., Chapin, F. S., Cornelissens, J. H. C., Díaz, S., Garnier, E., .. Navas, M.-L. (2008). Scaling environmental change through the community-level: A trait-based response-and-effect framework for plants. Global Change Biology, 14, 1125-1140. https://doi.org/10.1111/j.1365-2486.2008.01557.x

Tessier, A. J., Leibold, M. A., \& Tsao, J. (2000). A fundamental trade-off in resource exploitation by Daphnia and consequences to plankton communities. Ecology, 81, 826-841. https://doi.org/10.1890/00129658(2000)081[0826:AFTOIR]2.0.CO;2

Tranvik, L. J., Downing, J. A., Cotner, J. B., Loiselle, S. A., Striegl, R. G., Ballatore, T. J., ... Weyhenmeyer, G. (2009). Lakes and reservoirs as regulators of carbon cycling and climate. Limnology and Oceanography, 54, 2298-2314. https://doi.org/10.4319/lo.2009.54.6_part_2.2298

Trenberth, K. E. (2011). Changes in precipitation with climate change. Climate Research, 47, 123-138. 
Utermöhl, H. (1958). Zur Vervollkommnung der quantitativen Phytoplankton-Methodik. Mitteilungen der internationalen Vereinigung für theoretische und angewandte Limnologie, 9, 1-38.

Venables, W. N., \& Ripley, B. D. (2002). Modern applied statistics with S, 4th ed. New York, NY: Springer. https://doi.org/10.1007/978-0-38721706-2

Violle, C., Navas, M.-L., Vile, D., Kazakou, E., Fortunel, C., Hummel, I., \& Garnier, E. (2007). Let the concept of trait be functional!. Oikos, 116, 882-892. https://doi.org/10.1111/j.0030-1299.2007.15559.x

Wickham, H. (2009). ggplot2: Elegant graphics for data analysis. New York, NY: Springer. https://doi.org/10.1007/978-0-387-98141-3

Williams, P., Whitfield, M., Biggs, J., Bray, S., Fox, G., Nicolet, P., \& Sear, D. (2004). Comparative biodiversity of rivers, streams, ditches and ponds in an agricultural landscape in Southern England. Biological Conservation, 115, 329-341. https://doi.org/10.1016/S0006-3207(03)00153-8

Winfree, R., Fox, J. W., Williams, N. M., Reilly, J. R., \& Cariveau, D. P. (2015). Abundance of common species, not species richness, drives delivery of a real-world ecosystem service. Ecology Letters, 18, 626635. https://doi.org/10.1111/ele.12424

Yachi, S., \& Loreau, M. (1999). Biodiversity and ecosystem productivity in a fluctuating environment: The insurance hypothesis. Proceedings of the National Academy of Sciences of the United States of America, 96, 1463-1468. https://doi.org/10.1073/pnas.96.4.1463
Ye, L., Chang, C. Y., García-Comas, C., Gong, G. C., \& Hsieh, C. H. (2013). Increasing zooplankton size diversity enhances the strength of top-down control on phytoplankton through diet niche partitioning. Journal of Animal Ecology, 82, 1052-1061. https://doi.org/10.1111/ 1365-2656.12067

\section{SUPPORTING INFORMATION}

Additional Supporting Information may be found online in the supporting information tab for this article.

How to cite this article: Verbeek L, Vanhamel M, van den Berg E, et al. Compositional and functional consequences of environmental change in Belgian farmland ponds. Freshwater Biol. 2018;63:581-596. https://doi.org/10.1111/fwb.13095 